\title{
Economic, social and environmental dimensions of PHEV in the Smart Grid
}

Authors:

Christopher J. Bennett

Markos Katsanevakis

Rodney A. Stewart

Griffith School of Engineering, Griffith University, Queensland, Australia

\section{Summary}

Overcoming the technical hurdles to implementing plug-in hybrid electric vehicles (PHEV) technology into the smart grid is only one aspect of this disruptive transitional process. To ensure the rapid diffusion and efficient integration of PHEV in the smart grid, a range of governance, economic, social and environmental dimensions must also be considered and challenges addressed. Providing a robust governance framework is paramount, as it will drive both positive and perverse industry behaviours. Such frameworks must provide a set of rules and incentives to promote a stable market environment for PHEV roll-out over the long-term. Importantly, a well-designed governance framework will underpin the necessary economic thrust for an PHEV market to get established and grow. Such business drivers are sometimes not immediately obvious and are hard to quantify under current market conditions, such as quantifying the monetary benefits of distributed PHEV for the purpose of grid peak demand management and control. The economic drivers of PHEV are largely related to the capacity and related cost of energy storage and the provision of distributed power systems for resupplying them as required. Social dimensions are often multi-faceted and complex, but without convincing consumers that PHEV is a necessary transformative technology that is also economically and environmentally superior to traditional transportation methods, PHEV will never gain sufficient traction. Moreover, many people are still not convinced that the battery systems used in PHEV, which are mostly composed of Lithium, are sustainable. Proven cradle-to-grave environmentally friendly sourcing and life cycle management strategies for PHEV batteries is essential to ensure that this technology is acknowledged as a better solution than traditional liquid and gas transport fuels. To seize the full suite of opportunities and benefits available from PHEV technology, all of these intertwined challenges must be addressed in an integrated manner. Untangling these issues and many others and then formulating multi-pronged strategies to overcome them in a concurrent fashion, is a challenge, but one which must be undertaken in order to progress PHEV diffusion in society globally. This chapter seeks to unpack these four non-technical dimensions to PHEV diffusion. It will look at the 
opportunities and benefits related to each dimension along with the associated challenges and strategies to address them.

\section{Introduction}

While plug-in hybrid electric vehicles represent a significant opportunity for society, there are a range of economic, social and environmental barriers that need to be addressed before it becomes the predominant transport technology. The economic, social and environmental dimensions are complex, multifaceted and interrelated.

In the economic dimension, decision makers need information on how PHEV will affect people's behaviours, what would influence the uptake of electric vehicles and what would be the impacts on infrastructure such as the electricity grid. With this information, decision makers can then craft implementation frameworks that better consider the regulatory requirements as well as price incentives to achieve the best outcome for society and owners of electric vehicles. To do so, questions needs to be asked, such as what effects will PHEV charging from the electricity network have? What incentives can be put in place to minimise adverse impacts? And, what benefits can be yielded through EV proliferation and how can this proliferation be achieved? Using economic theory, these questions are answered under two key concepts: Smart Electric Vehicle Charging and Electric Vehicle as Distributed Energy Resources.

The social dimension concerns itself with the attitudes and beliefs of individuals in society and PHEV. When individuals, potential owners and consumers of PHEV, concern themselves with a mode of transportation they consider their needs and wants against the knowledge that they have at hand. Questions of convenience, trust of the technology, safety and risk enter their minds. In turn, industry decision makers should take into account whether or not PHEV will fulfil the potential owner's want for autonomy (travel where and when they want to travel), which they have come to expect since the introduction of the car. Understandably, owners will be concerned about PHEV purchase costs, servicing and maintenance requirements and costs, resale value over time, and life cycle ownership costs.

The environmental dimension addresses the environmental impacts that PHEV have from cradle to grave in comparison to vehicles currently available on the market. It is essential that PHEV be weighed up against conventional and other new transport technologies, and its' environmental credentials assessed in terms of air quality, greenhouse gas emissions, pollutant runoff, battery waste management, to name a few. If 
the rollout of PHEV will provide better long-term conditions for human health and the environment, then it may be considered over conventional transport technologies even if it has a higher life cycle cost. The first section of this chapter addresses the critical economic dimensions of widespread PHEV implementation.

\section{Economic Dimension}

At present, the greatest challenge to the societal uptake of PHEV is economic in nature. On an aggregated level, the direct cost of the vehicle to consumers, the costs endured by electricity network operators and the costs of managing waste are all factors. Analysis of the charging operations of PHEVs, the ancillary functions that PHEVs can provide and the associated control systems are required in order to reduce costs and, in turn, yield greater benefit. PHEV charging may have a range of impacts on the electricity network due to the anticipated variability in PHEV charging, how rapidly PHEVs charge and when they are charging. Potential ancillary functions are 'supporting the grid', which acts to distribute energy resources, potentially mitigating negative economic affects or providing net benefits to network operators. In the event that PHEVs became cost-neutral compared to conventional combustion engine vehicles, additional waste management infrastructure would be required to deal with the increased quantity of battery waste.

The residential LV distribution network's load has two main characteristic profiles: summer and winter (illustrated in Figure 7.1 [Bennett et al., 2014a]). The load profile for summer is such that the lowest loads are experienced during late night and early morning. From early morning onwards, the network load gradually increases until the peak demand period is approached. There is a large increase in load during peak demand periods, typically occurring between $5 \mathrm{pm}$ and $9 \mathrm{pm}$, dependent upon the specific network. The winter load profile also experiences the least demand during late night and early morning. Conversely, two peak demand periods occur between 8 am and $10 \mathrm{am}$, and $5 \mathrm{pm}$ and $9 \mathrm{pm}$. Peak demand periods have the greatest effect on the design and network augmentation schedules of the network, such that the network must accommodate these periods so no failures occur. In turn, significant investment is made to the network to ensure continuous operation for proportionally brief operational periods (Nelson et al., 2011 \& Simshauser et al., 2011). The widespread uptake of PHEVs in residential areas would have a profound influence on network infrastructure. If PHEVs were to charge during peak demand periods, networks would run closer to full capacity, possibly warranting network augmentation (Lemoine et al., 2008; Putrus et al., 2009 \& Qian et al., 2011). As a significant portion of the cost of electricity derives from its transmission and distribution, a consequence would be an increased electricity cost to consumers. Thus, the utility of PHEVs to owners would decrease, and those not owning them would be subsidising network augmentation. To avoid this, the design and operation of PHEVs should be such that they are not 
economically negative. This can be achieved by PHEVs supporting the grid. A number of possibilities for PHEV support of the grid are pending quantitative research prior to implementation:

- smart charging of PHEVs;

- PHEVs as distributed energy resources;

- the use of PHEVs to utilise pre-existing solar PV generation.

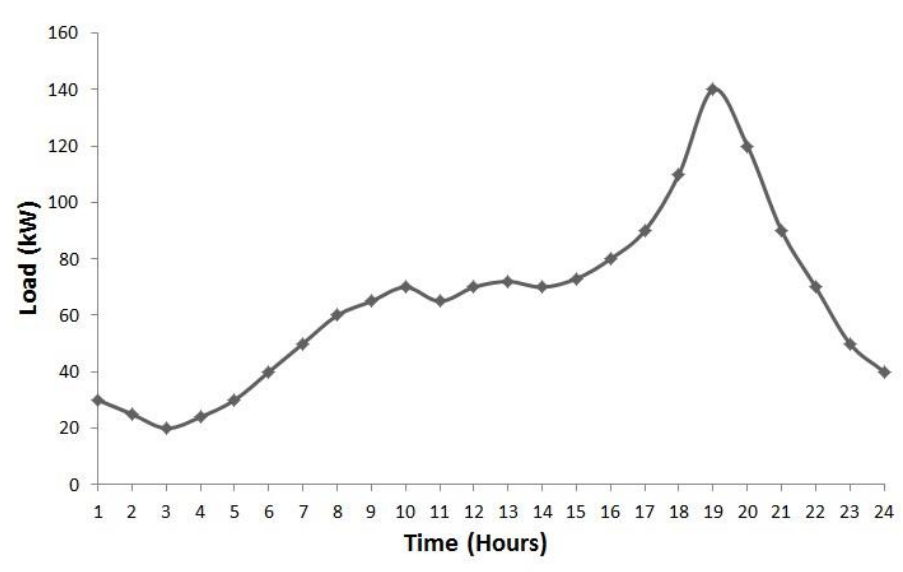

a) Summer Load Profile

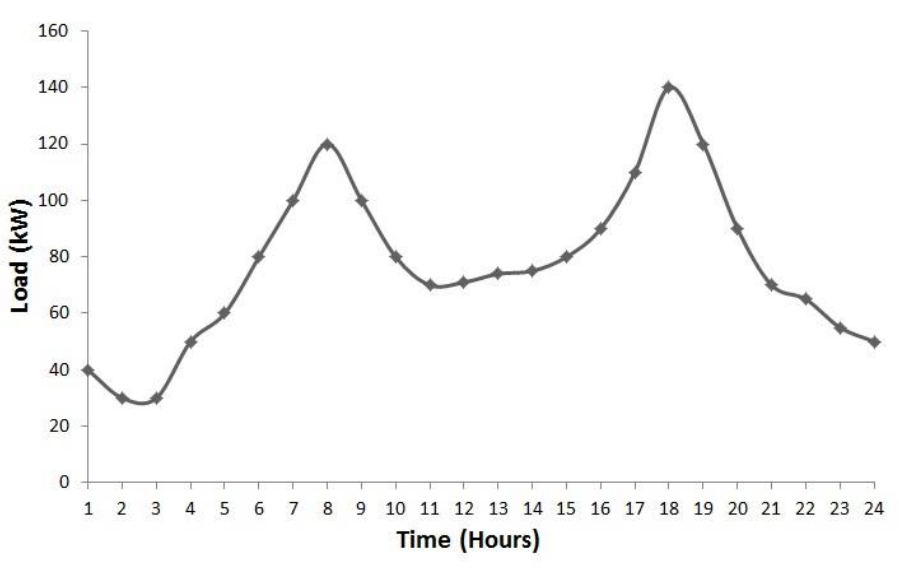

b) Winter Load Profile

Figure 7.1: Summer and winter load profiles

\subsection{Smart Electric Vehicle Charging}

Smart charging of PHEVs entails charging in a way that does not detrimentally affect the grid. An example of smart charging would be restrictions on when PHEVs can be charged. A second example is charging PHEVs from energy sources not directly connected to the electricity grid. Curtailing PHEV charging periods could be enacted through tariffs, regulatory dicta or network operator communications systems.

Time of use tariffs and a demand management technique require that the price of electricity is proportional to its value at different points throughout the day (Strbac, 2008; Deilami et al., 2011 \& Qian et al., 2011). Figure 7.2 displays the value of electricity over time. As discussed, network design and augmentation are dependent on the load experienced during peak demand periods. As the load in peak demand periods approaches network capacity, network augmentation may be required. In turn, as supplying the capacity to meet peak demand dictates the price of electricity, time of use tariffs would set the highest price of electricity during this period. Late night and early morning would have the lowest price as these times experience the lowest demand. Price throughout the rest of the day would change to reflect the intersection of demand and supply curves. As consumers respond to price signals beyond the elastic region, they will alter their behaviour to consume electricity and charge PHEVs in accordance with their 
willingness to pay (Lemoine et al., 2008). Price sensitive consumers will shift their non-essential electricity consumption to periods in which the price is low. Non-price sensitive consumers will pay for electricity according to its value, so will be paying for the capacity required of the network to supply electricity during peak demand periods.

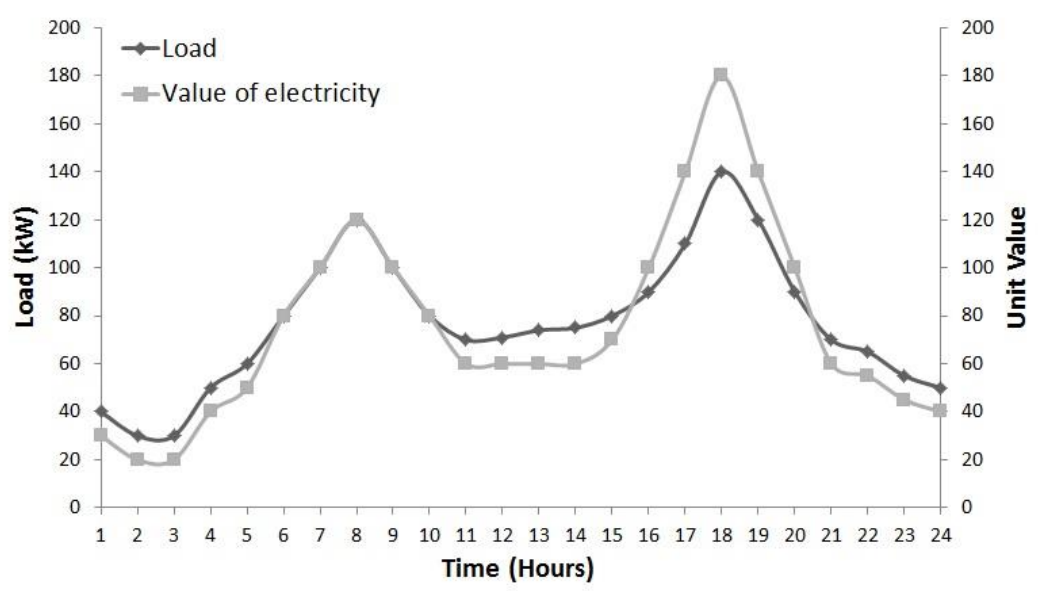

Figure 7.2: Value of electricity versus time

Figure 7.3 presents the results of implementing a time of use tariff. Included are electricity supply and morning and evening electricity demand curves. The original price of electricity curve is set at 58 price units. The intersection of the demand curves and the original price curve establishes the original consumption quantities in the morning $\left(Q_{m 1}\right)$ and evening $\left(Q_{e 1}\right)$. In the scenario presented, the time of use tariffs are set at the value of electricity for the morning and evening periods - that is, the intersections of the demand curves with the supply curve. This sets the new consumption quantities for the morning $\left(Q_{m 2}\right)$ and evening $\left(Q_{e 2}\right)$. Allowing the price of electricity to reflect its value means that in the morning the quantity of electricity consumers will increase from $Q_{m 1}$ to $Q_{m 2}$. In the evening, electricity consumed will decrease from $Q_{\mathrm{e} 1}$ to $Q_{\mathrm{e} 2}$. Time of use tariffs are set to reflect the value of electricity at different times, flattening the load profile. 


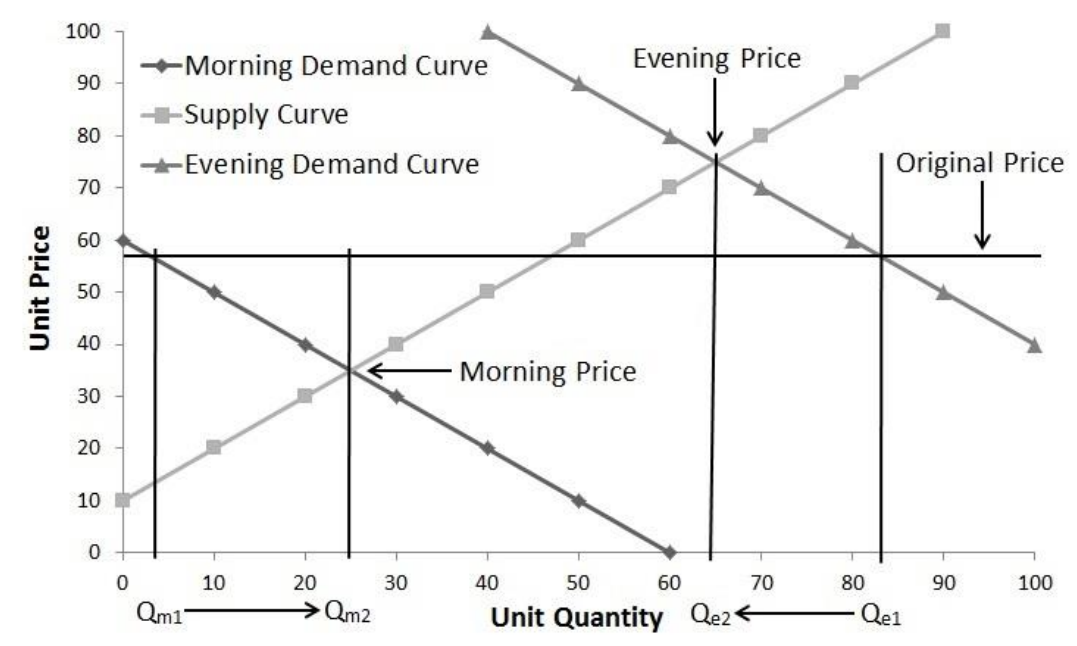

Figure 7.3: Time of use tariff

Regulating PHEV charging from the electricity network by restricting the periods in which they are allowed to charge could support the grid. If restrictions were implemented, they would be during peak demand periods such as 8 am to 10 am in the winter load profile and 5 pm to $9 \mathrm{pm}$ during summer and winter load profiles. Consumers would be obliged to shift vehicle charging to periods of low demand. Benefits of supporting the grid would be the greater utilisation of electricity network infrastructure during non-peak demand periods, or customers finding alternative ways of charging PHEVs. These would mean that network operators and generators would be able to recover costs of network investments over greater periods, reducing the marginal cost of supplying electricity. Figure 7.4 presents the change in marginal cost $\left(\mathrm{MC}_{1}\right.$ to $\left.\mathrm{MC}_{2}\right)$ for a given investment, in which total cost does not change and units produced increases. $A$ neutral effect of the regulatory approach is that PHEVs will not contribute to load during peak demand periods. A drawback of this approach compared to time of use tariffs is that customers lose autonomy. Some consumers may prefer to pay a higher price for electricity during peak demand periods and charge their vehicles. Some instances may necessitate PHEV charging during these periods to fulfil important tasks or attend emergencies. The loss of autonomy may be mitigated by commercial charging stations. 


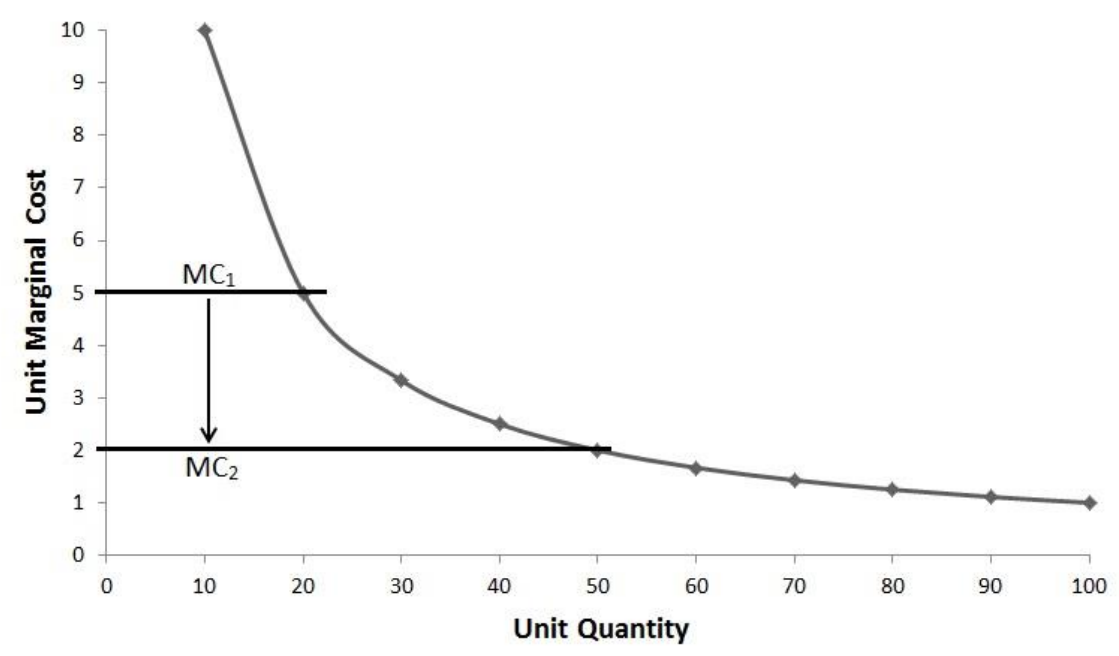

Figure 7.4: Marginal cost of supplying electricity

Through the installation of a network communication system, the network operator would have to include EVs into its portfolio of load management practices. In some networks, this would include ripple control of electric hot water systems and pool pumps (Deilami et al., 2011). As the electricity network demand approaches capacity, the network operator may opt to engage in remedial measures such as load shedding. In turn, PHEVs would be prevented from charging and contributing to demand as the network approaches capacity. Additional uses of a network communication system may include remote scheduling of PHEV charging and the use of PHEVs to store excess generation. Similar to possible regulations, the network operator may dictate that PHEVs are charged during non-peak demand periods, reducing the marginal cost of generating and distributing electricity. Unlike the regulatory approach, the network operator would be free to experiment and discern the optimal scheduling arrangement, which produces the best outcomes for the customer and the electricity network. Instances occasionally occur in which there is excess generation over demand; in such circumstances, PHEVs can absorb excess generation. The inclusion of PHEVs in the portfolio of load management practices and their operation would be at the discretion of the network operator, and its obligation to ensure the stability of the electricity network and prevent brown or black outs.

\subsection{PHEVs as Distributed Energy Resources}

PHEVs have the potential to act as distributed energy resources (DERs) due to their energy storage capabilities. The use of PHEVs as DERs would yield functionality similar to more conventional grid-based energy storage technologies, such as fixed batteries (Brooks, 2002; Andersson et al., 2010 \& Peterson, 2010). Differences between the two technologies reside in the operational control and how economic value is created. 
The conventional operation of energy storage is such that during low demand periods, energy storage systems absorb energy generated and discharge it during peak demand periods (Mohd et al., 2008). This conventional operation is known as 'peak shaving and valley filling', illustrated in Figure 7.5. This can be achieved by time-of-day heuristics or more advanced methods involving the use of load forecasts, and the optimisation of charge and discharge schedules with the use of this information. The use of PHEVs to perform this function adds a greater degree of complexity to the control operation, due to PHEVs' discharge of energy into the grid. The use of PHEVs as energy storage means that there will be no fixed energy storage capacity, and the network operator or control system will have no prior knowledge of when a customer will use their PHEV or when it would be available to discharge energy into the grid. To use PHEVs adequately for energy storage, a number of systems would need to be created, such as load forecast models, energy storage availability forecast models, discharge schedule optimisation and dynamic discharge optimisation.

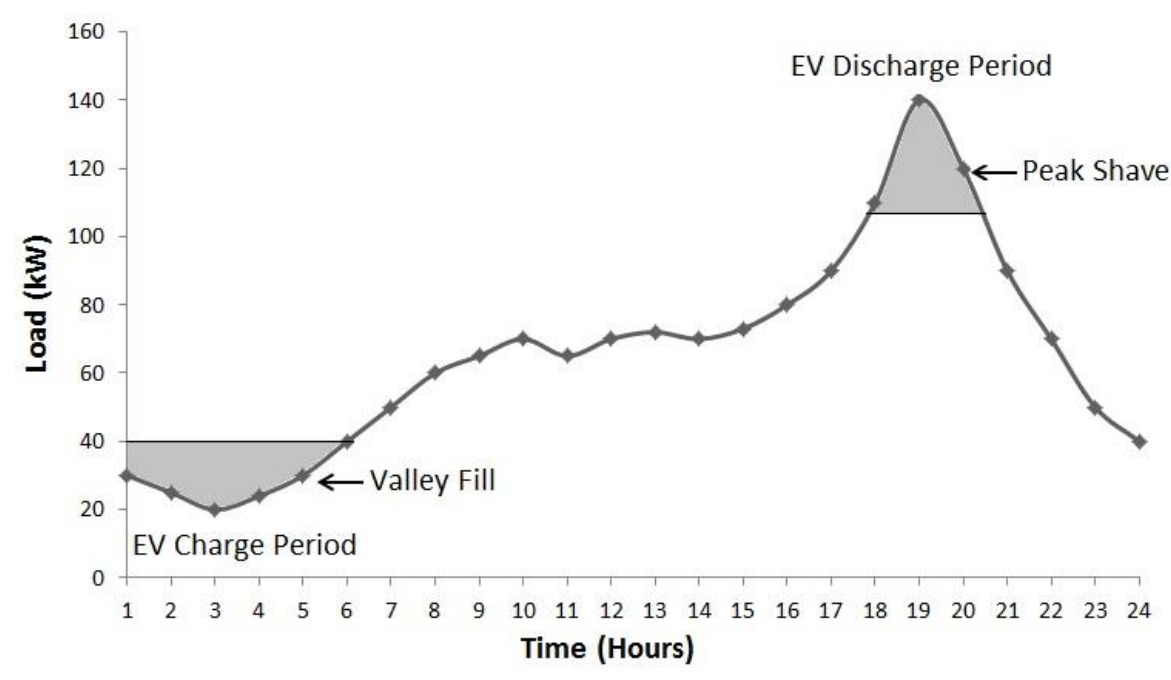

Figure 7.5: Peak shave and valley fill

The development of the necessary forecast models fall under two categories, depending on whether the system is deterministic or non-deterministic in nature. Load on the electricity network follows a deterministic pattern, with weather accounting, temporal and autoregressive variables accounting for much of the observed variance (Bennett et al., 2014a \& Bennett et al., 2014b). In turn, load forecast models are usually deterministic, and can be developed through techniques such as regression, autoregressive models with exogenous variables and machine learning techniques (neural networks and support vector machines) (Bennett et al., 2014a \& Bennett et al., 2014b). These techniques have benefits and drawbacks. Regression is the simplest technique to use, yet requires a-priori data analysis to identify the type of relationship for which to programme a variable. Autoregressive models require information 
about future load on the network to be found prior to demand, through identifying periodic patterns. External variables can be included with autoregressive models, to increase accuracy. Machine learning techniques are able to identify non-linear relationships between dependent and independent variables. $A$ drawback of machine learning techniques is that they require extensive computational resources.

Energy storage capacity available as DERs would be categorised as a non-deterministic system (Fluhr et al., 2010 \& Qian et al., 2011). There is no way to know the behaviour of customers in advance, or the availability of PHEVs to be used according to direct relationships with exogenous variables. Consequently, forecasting available energy storage capacity would rely on estimating the availability of a certain number of PHEVs and their capacity (Fluhr et al., 2010 \& Qian et al., 2011). To do this, a stochastic modelling technique (or techniques that are similar) would be required, to develop energy storage capacity forecast models. As demonstrated in Figure 7.6, a stochastic model is used to produce a probability distribution of a random variable (availability of energy storage capacity) as a function of historical time series data, random variables and deterministic influences. The values in the probability distribution coinciding with the highest occurrence probabilities establish the range of likely values that a scheduling algorithm should consider and optimise therein. Variables in forecasting what constitutes available energy storage capacity include:

- the number of PHEVs available;

- the charge state of the available PHEV;

- the phase of the electricity line the PHEV will be attached to; and

- for how long the PHEV will be available.

Optimising the discharge schedule and operating the system in real time adds complexity, requiring indepth investigation before implementation.

The reduction in peak demand from the use of energy storage reduces the load on pre-existing infrastructure, in effect increasing network capacity. Economic value is created when installation of energy storage is more cost effective than network augmentation. The benefit of using PHEVs rather than installing fixed energy storage systems is that the costs of providing energy storage infrastructure is born by the PHEV owner rather than the network operator. The network operator yields value in the reduction of load via network augmentation deferral, without associated costs. The feasibility of PHEVs as DERs depends on the consistency of the PHEV's availability in supporting the grid. It is reasonable to expect that PHEV owners will oppose the use of their vehicle as a DER without compensation greater than the associated costs of allowing the use of their PHEV. To increase the reliability and availability of energy storage capacity, owners of PHEVs should be incentivised or compensated. Ways to do so include the creation of bidirectional time of use tariffs, or static feed in tariffs. 


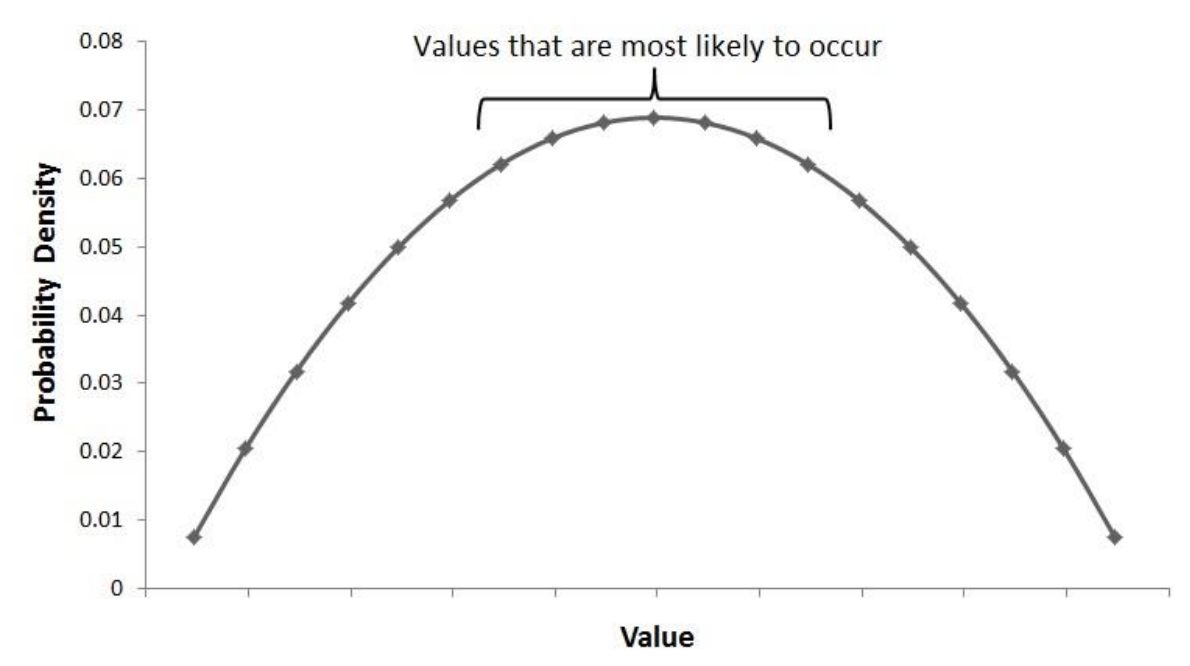

Figure 7.6: Stochastic forecast

Bidirectional time of use tariffs require that the price offered throughout the day for both electricity consumption and power discharge (feed in tariff) reflects the value of electricity at the respected time (Brooks, 2002; Peterson, 2010 \& Lopes et al., 2011). There would be a trade-off for the PHEV owner between the use (or potential use) of the vehicle and earning revenue from the use of PHEVs as a DER (Lopes et al., 2011). The use (or potential use) of the vehicle would be the owner's opportunity cost. If the discharging portion of the bidirectional tariff outweighs the opportunity cost and the cost of charging the vehicle, an increased energy storage capacity would be available for discharging. As the value of the opportunity cost to owners will fluctuate based upon external variables, the network operator may have to offer higher tariffs during different times of year, to achieve the desired energy storage capacity.

A static feed in tariff would operate similar to residential solar PV feed in tariffs. For a given amount of energy discharge into the grid, the owner would be receiving a fixed amount of money in return. The tariff should be offered for a specific duration, as an incentive to customers to invest in energy storage devices. A potential drawback of this tariff regime is that the tariff may not reflect the actual value of the system installed. In turn, it is more costly for this regime to exist than the conventional network augmentation scheme. Additional regulations would be required to ensure that energy storage systems discharge into the grid when load is high.

Figure 7.7 presents the result of a static feed in tariff, or the partial result of a bidirectional tariff implementation. The figure includes the electricity supply curve, the evening electricity demand curve and the original fixed price. The intersection of the original fixed price represents the quantity of electricity PHEV owners that are willing to supply, $Q_{s 1}$. The intersection of the evening demand curve and the supply curve represents the willingness of PHEV owners to supply a quantity of electricity, $Q_{s 2}$. The increase in 
quantity supplied from $Q_{s 1}$ to $Q_{s 2}$ suggests that the benefit yielded to owners was greater than the opportunity cost of not supplying electricity to the grid. Based on the principles of supply and demand, the implementation of a compensation arrangement will increase the reliability of energy storage capacity.

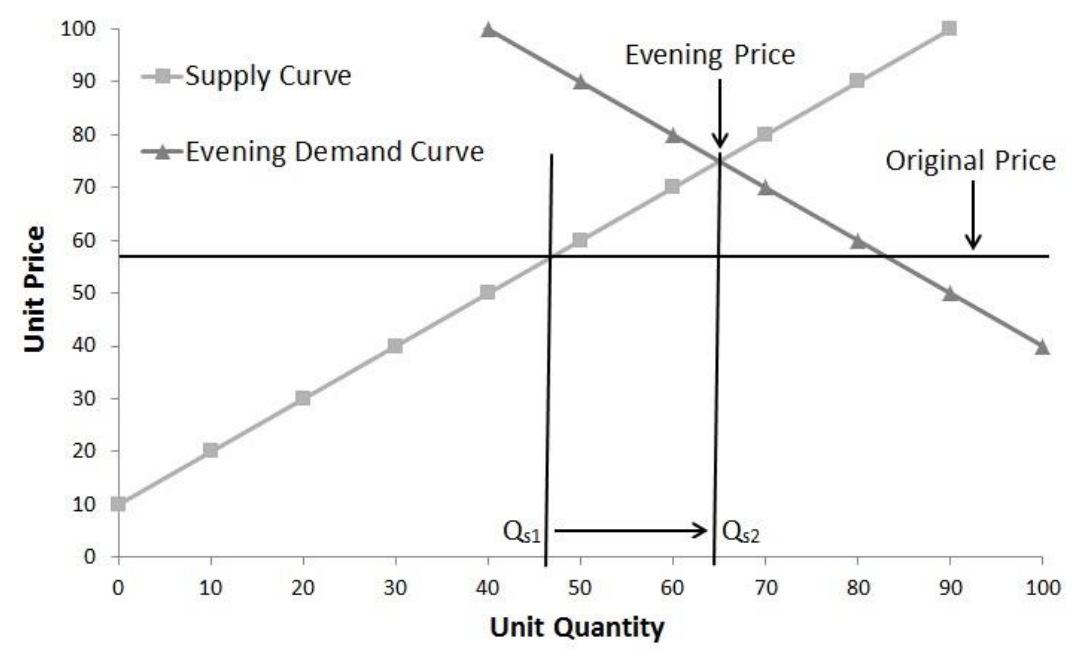

Figure 7.7: Compensation to EV owners

\section{Social dimension}

A number of social challenges need to be addressed before the widespread diffusion of PHEV can be realised in advanced economies. Outlines of some of the key challenges follow.

\subsection{Convenience}

Since the advent of the car, urban dwellers have utilised the convenience of owning one or more vehicles per household, available for use at any time of day. The Internal Combustion Engine (ICE) and its reliance on liquid petrol or gas has meant that this transport option is always available, as long as fuel supplies (and the finances to purchase them) are available, almost always the case in advanced economies. The proliferation of petrol stations means that even in a geographically large country such as Australia, with one of the lowest global population densities, rarely will 500 kilometres be travelled without the presence of a petrol station. Further, fuel tanks deplete after one to two weeks (based on average consumption and filling times of five to ten minutes). For workers and families in advanced economies, the ICE vehicle is a convenient means of travelling within and between destinations at any time.

The PHEV offers the same opportunity for travel but possesses some technological limitations at present, which reduce the convenience of the PHEV if compared to ICE technology. First, the price, frequency and length of charging are much higher. Long charging times are particularly inconvenient when travelling long 
distances as they force motorists to stop frequently, after travelling around 300-500 kilometres. Further, motorists must wait while their vehicle charges. Conversely, motorists of conventional vehicles occasionally drive for up to 14 hours per day in one sitting, with only short rest breaks. 'Battery swap' stations have been considered and could result in much quicker stops for long-distance travellers, but the costs and warranty aspects of such systems requires further assessment and testing (Mak et al. 2013). Further, rapid battery charge technology is being researched and could reach develop so that battery charging occurs rapidly (Mak et al. 2013).

Installing PHEV charging infrastructure is a commonly discussed barrier to the widespread adoption of PHEV. This 'chicken and egg' scenario will continue to prevent a greater adoption of PHEVs in many cities. If there is no market for PHEV charging, there is no incentive to build charge stations; if there are not sufficient PHEV charge stations, consumers will be reluctant to transition to driving PHEVs. Only strong believers in the benefits of PHEVs will suffer the inconvenience, with the majority only moving to PHEVs if they offer similar convenience as ICE vehicles. Alternatively, the average person will transition if the price of petrol reaches a point where ICE vehicles are no longer financially viable. For the building of charging stations, initial government support is required, in the form of subsidies, taxation relief and technology standardisation enforcement (such as charging plugs and electrics) (Steinhilber et al. 2013). A worst-case scenario would be if the power electronics of different vehicles and stations were incompatible (Khan and Khan, 2013).

\subsection{Uncertainty, Trust and Equity}

For all major technology transformations, the designer and merchant must be able to dispel consumer uncertainty and generate a level of trust (Ziefle et al. 2014). This is particularly difficult when a new technology competes with a proven technology (such as the ICE vehicle) largely viewed as safe, reliable and understandable. Before trust and loyalty can be established for PHEV technology, uncertainty must be reduced for the following issues:

- After sales service and cradle-to-grave maintenance of PHEVs. Vehicles require continual maintenance and repair. PHEV manufacturers and dealers should provide buyers with long-term warranties and access to service centres. As the greatest area of uncertainty for PHEVs is the 'true' reliable life of batteries, long-term warranties of eight or more years are required, to instil trust in consumers as well as trained and competent technicians to service PHEVs reliably (Heymans et al. 2014). 
- PHEV battery technology lifespan, redundancy and refurbishment costs. If battery technology has a reliable life of only five to eight years, and the replacement of battery packs after this period is substantial (30 per cent of a new vehicle purchase price), the second-hand market for PHEVs will be very poor. The costs of installing new or refurbished battery packs should be low enough to ensure that PHEVs have a life in the second-hand car market, a key feature of the traditional ICE vehicle market, in which sellers would expect around half of the original car value back after approximately five years.

- Proliferation of charge stations and points. Purchasers of PHEVs will want to see that they can charge their vehicles reliably for a range of circumstances. This includes short-, medium- and longdistance travel scenarios. Charge stations will not be constructed until there are a viable number of PHEVs to support them, and PHEVs will not be purchased until there are sufficient charge stations and points for customers. Consumers also require sufficient information on where charge points are located, and mobile applications - such as PHEV Charging Station Locator and Plugshare-are being offered in the United States.

Further, to avoid public backlash against PHEV technology, there must also be social equity considerations. A key aspect of PHEVs is that they require charge points/stations, at home or work. This means that a range of urban planning considerations for cities and regions must be considered requiring incorporation of either short or long-charge technology. With existing multi-residential buildings, how will limited charge points be assigned to residents? Within the workplace, who will have access to parks with charge points? How are these assigned-on a first-in basis, according to level in the organisation, the necessity to charge or other considerations? A range of equity issues regarding charging access will present should PHEVs become commonplace.

\subsection{Perception of Poor Safety}

Consumers have a few safety concerns about PHEVs. Such concerns can be addressed easily through appropriate testing and compliance. However, although isolated, safety incidents involving PHEVs are more newsworthy than ICE vehicle safety incidents, so are more likely to influence perceptions of PHEVs negatively. Below are consumers' main safety concerns:

- Battery system catching fire. A number of cases have been reported in which the Lithium Ion batteries commonly used in PHEVs catch on fire (Lu et al. 2013). These have often been blamed on vehicle accidents that compress the space in which batteries are contained (Lu et al. 2013). 
Incidents are not necessarily frequent but they are reported widely in the media, as this is a relatively new technology, meaning that public perception is affected. Extensive laboratory and field testing is being undertaken to ensure the long-term safety of PHEV battery systems, to ensure their safety.

- Safety related to PHEV low noise. Early PHEVs and hybrid vehicles were criticised for their lack of noise (their engines are silent), as pedestrians could not hear them coming, thereby leading to pedestrian incidents (Cocron and Krems, 2013). This was especially problematic for the hearing impaired who relied on noise to determine whether a vehicle was coming (Cocron and Krems, 2013). A number of standards have been introduced to ensure that PHEVs and hybrid cars emit noise so that they can be heard by pedestrians. This issue is being worked on, and should not be an ongoing impediment to the adoption of PHEVs.

\subsection{Public Perceptions and Overcoming Resistance to Change}

If charge facilities and technologies (especially the charge rate) improve, an PHEV could provide a similar or better travel experience for most daily commuters. However, the perception still entrenched in many peoples' minds is linked to earlier PHEV technologies that were expensive to purchase, had poor resale value and limited range. A successful PHEV market will flourish when these perceptions diminish through successful city-scale PHEV roll-outs, rapid improvements in technology and through educating the riskaverse consumer. A key platform for improved perceptions of PHEV technology is information and social marketing of the benefits of PHEVs. Independently produced information on PHEV performance compared to ICE for a range of key performance indicators (charge time, cost of ownership, environmental aspects, travel distance etc.) relevant to consumers should be provided.

People are often resistant to change, so it is important that PHEV promoters transition people in a subtle manner. PHEVs are still considered a revolutionary technology by the mainstream population, not just a logical transition for vehicles. Manufacturers have used a number of strategies to transition people from one technological generation to the next.

\section{Environmental dimension}

Motivation for replacing conventional cars with PHEVs can originate in ever-increasing fuel prices, as well as environmental concerns associated with sustainable living, such as the desire to improve air quality in urban areas by replacing conventional vehicles and their pollutants. Gas emissions from hybrid or purely 
electric vehicles can be significantly reduced or totally absent, a fair statement when only the exhaust pipe of the PHEV is considered, excluding harmful emissions resulting from the thermal electricity generation necessary for charging PHEV batteries. The aforementioned example is indicative of narrow examination of the matter; therefore, to study the environmental impact thoroughly, the effects of batteries, fuel, lightweight materials, electricity generation and so on should be included. Further, the examination should include the life phases of the vehicle and the outcome should be compared to the environmental impact caused by vehicles of different technologies. The above are taken into consideration during a life cycle assessment (LCA); therefore, this principle is discussed in this section.

\subsection{LCA for PHEVs and Consideration of Further Automotive Technologies}

For a comprehensive assessment of PHEVs as entities, beyond the utilisation period of the vehicle, phases such as extraction of raw materials and recycling, reuse or waste management should be included in the LCA. This is so a full account of the lifetime environmental effects resulting from components incorporated in vehicles can be taken. Such components (apart from batteries) can be electric motors and power electronics. Common to different automotive technologies are the chassis, wheels, car interior and so on. The phases of a complete LCA, from cradle-to-grave, are presented in Figure 7.8 (Renaldi et al., 2013; Messagie et al., 2010; Humphreys et al., 1996).

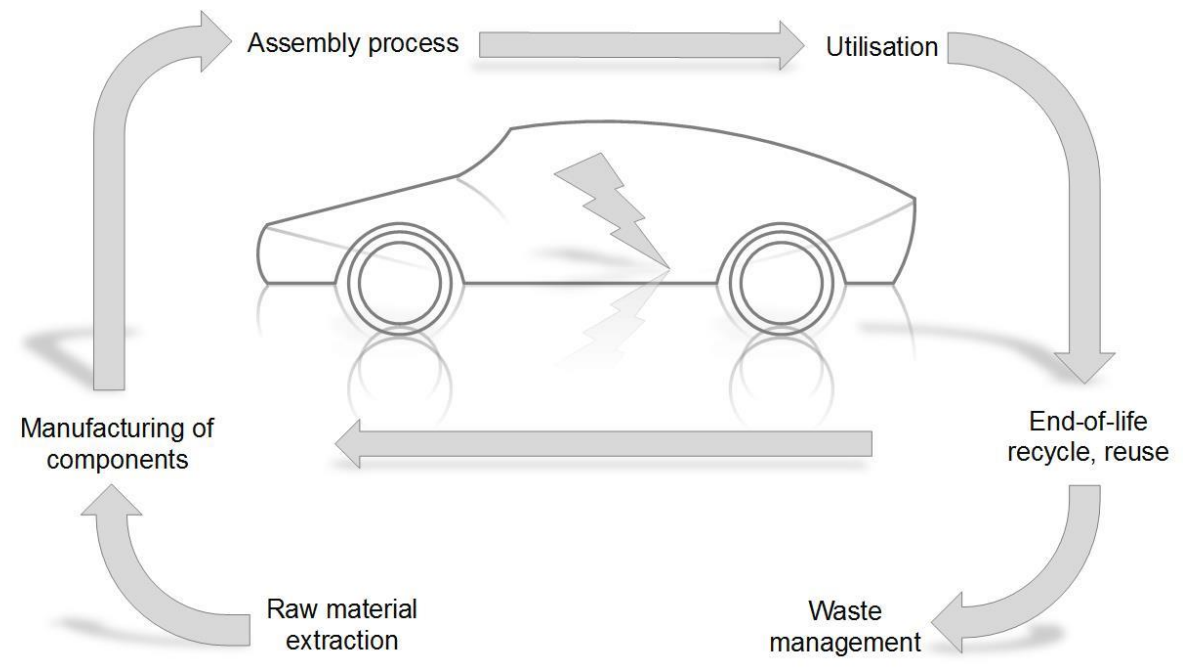

Figure 7.8: Life cycle assessment phases

The examination of the LCA phases and the comparison of the results between pure PHEVs, hybrid and conventional vehicles is of great importance in ascertaining the environmental impact for each technology. Another outcome from the LCA is to identify whether negative environmental effects have shifted from the 
utilisation phase to other life cycle periods. In terms of information to include in the assessment, a cradleto-grave approach should be considered (rather than a cradle-to-gate, which does not account for the utilisation and end-of-life phases), containing material consumption, energy consumption and emissions during periods such as those presented in Figure 7.8. In terms of fuel, the well-to-wheel process should be followed to include impact related to fuel production, distribution and consumption in the vehicle. In addition, the environmental effect from the generated power intended for charging PHEV batteries should also be factored into any assessment. A more detailed description of the information can be found in Humphreys et al.'s study (1996). The stages concerning electrical energy production for PHEVs, namely, fuel production and transportation, electricity generation, transmission and distribution, battery charging and PHEV operation should be included. For a conventional vehicle, the aforementioned stages are adapted to crude oil extraction and transportation, oil refining, gasoline transportation, vehicle fuelling and operation (Renaldi et al., 2013; Messagie et al., 2010; Humphreys et al., 1996).

\subsection{Environmental Impact Comparative Assessment}

The outcome of the LCA for different vehicle technologies can be expressed through the following (Renaldi et al., 2013; Messagie et al., 2010; Humphreys et al., 1996):

- air acidification;

- eutrophication;

- human health; and

- greenhouse effect.

For batteries - and particularly for the Lithium Ion (Li-ion) type found in cutting edge technology PHEVsthe extraction of Lithium can be harmful to the environment, and in the case of the Nickel Metal Hydride (NiMH) type, mainly available in obsolete PHEVs. Therefore, recycling must be performed to mitigate the extent to which nickel influences air acidification. As long as battery recycling is performed, PHEVs have a lower acidification impact than hybrid and conventional vehicles, but without recycling, the impact is significantly increased. By end-of-life, a hybrid vehicle without battery recycling would pollute more than a conventional vehicle. In general, Li-ion technology is more environmentally friendly and less threatening to the human health than NiMH technology. In the case of extensive aluminium use, there is a higher threat of ozone depletion, mainly due to the extraction and production phases. Conversely, when a battery reaches end-of-life it can be reused or recycled, so its overall environmental impact from cradle-to-grave can be reduced significantly. The assessment should also include total materials utilised, energy consumed 
and environmental residuals, for a comparison between PHEVs and conventional vehicles (Renaldi et al., 2013; Messagie et al., 2010; Humphreys et al., 1996).

In terms of eutrophication, conventional types of vehicles (diesel and petrol) have the highest impact, while PHEVs have the lowest, originating mainly from the production of the Lithium battery. To compensate for the weight increase caused by the batteries, the lightweight materials used in PHEVs achieve their target only if the utilisation phase of the vehicle is concerned, as their usage balances energy consumption and related greenhouse gas emissions. However, to create a thorough image of the environmental impact of the lightweight materials, the production/ manufacturing phase should be included. If magnesium and carbon fibre materials have been used, they have a more detrimental effect on human health than conventional steel. PHEVs' impact on human health is still lower than conventional vehicles, and it is a combination between raw material extraction, manufacturing process and vehicle assembly, along with tires and brakes wear and tear. On contrary, the ICE vehicle's negative effect on human health is related to fuel production, distribution and consumption, along with raw material extraction, vehicle assembly and so on (Renaldi et al., 2013 \& Messagie et al., 2010).

Petrol and diesel vehicles have the highest impact on greenhouse gas emissions, mainly due to their fuel consumption. Petrol produces the highest amount of greenhouse gases, reflected in the well-to-wheel phases-fuel production, distribution and consumption. In hybrid vehicles, emissions are reduced due to improved fuel consumption, but the impact is still considerable. Messagie et al., (2010) discusses that PHEVs have the lowest negative impact.

Further components necessary for the operation of PHEVs-such as electric motors and power electronics-contribute to the total environmental impact of the vehicle in terms of greenhouse emissions. These are estimated to be approximately two and three per cent of total emissions (Renaldi et al., 2013).

Another aspect associated with PHEVs is the generation of electricity to be used in the vehicles, and its environmental impact, depending on its origin. For instance, in the future where energy with be sourced from a range of non-renewable and renewable sources, PHEVs are more environmentally friendly than petrol vehicles. The more that renewable energy sources (RES) are integrated and utilised to power PHEVs, the more emission free the transportation will become. Conversely, a small conventional vehicle with improved fuel efficiency can have a lower environmental impact (such as on the greenhouse effect) than an oversized PHEV powered solely by coal or oil-fired thermal units. Further, in the case of thermal generation, capacity should be added by the utility, in order to supply the excess demand of PHEVs. The 
additional emissions must be registered in the LCA of the PHEVs, and also included should be emissions accruing from the utilisation of different types of units and variation in dispatch to supply the demand of PHEVs (Messagie et al., 2010; Humphreys et al., 1996).

4.3 Global metal reserves, production and pricing data related to vehicle batteries and electric motors

Another dimension related to the environment which needs to be explored is the adequacy of metal reserves required in the manufacturing process of EVs. Such metals are mainly related to the batteries and electric motors of the vehicles and in order to estimate the longevity of the different battery technologies, the resources and in turn reserves have to be examined as well as the treatment of batteries by the end of their life cycle has to be discussed.

In Table 7.1 (Chatzivasileiadi et al., 2013) are presented the reserves of the three main metals utilized in batteries while it is also presented the remaining period for each of them based on the reserves over the current annual demand for each. It can be seen that the reserves of Nickel and Lead are running out but to the contrary, reserves of Lithium are expected to last for a considerable period of time. The values illustrated in Table 7.1 may change in the future particularly in case of Lithium and Nickel due to factors such as technological improvements, discovery of new reserves and recycling of the metals. These factors are expected to significantly affect the remaining period of the materials towards an increase as well as to limit their environmental impact.

\begin{tabular}{|l|l|l|l|}
\hline Metal & Reserves (ktons) & Annual demand (ktons) & $\begin{array}{l}\text { Remaining period } \\
\text { (years) }\end{array}$ \\
\hline Lithium & 13,000 & 34 & 382.35 \\
\hline Nickel & 80,000 & 1,800 & 44.44 \\
\hline Lead & 85,000 & 4,500 & 18.88 \\
\hline
\end{tabular}

Table 7.1: Global metal reserves (Chatzivasileiadi et al., 2013).

The evidence provided in Table 7.1 regarding the extended period of Lithium reserves is confirmed by Kesler et al., 2012 where it is deemed that resources are adequate to cover the current demand and even beyond the $21^{\text {st }}$ century provided that recycling of the batteries takes place. In the same work it is stated that the existing global Lithium resources are maintained in four main forms as follows:

- Pegmatite

- Brine 
- Unusual rocks

- Unusual fluids

According to Kesler et al., 2012, the Lithium resource in pegmatites is identified at $3.9 \mathrm{Mt}$, the Lithium resource in brine is expected to be $21.6 \mathrm{Mt}$ while the Lithium in unusual rocks and fluids adds up to $5.4 \mathrm{Mt}$. At this stage the attention needs to be brought on the fact that the expected resources have to be processed in order to be converted into reserves so Lithium can be produced at a reasonable cost. This observation has been made by Kesler et al., 2012, and it has been supplemented by the statement that examination of a number of other parameters has to be performed in order to find out about the feasibility of the conversion, for instance in case of brine deposits, brine constituents such as potassium and magnesium among others would prevent from processing.

Another challenge associated with the Lithium resources in brine which has to be addressed, is that $70 \%$ of the resources are located in four countries namely Argentina, Bolivia, Chile and China translated to a strategic advantage on their behalf. On the other hand, the Lithium resources in pegmatites are more scattered among different countries Kesler et al., 2012, this could be translated into reduced market domination of a small number of countries over others which is however partially true when considering that the expected resources in brine account for the $2 / 3$ of the total global resources. According to Goonan, 2012 the issue of market domination of a few countries is even more intense as it is reported that $75 \%$ of the global Lithium resources exist in just three countries i.e. Argentina, Bolivia and Chile while lowcost resource is also available in China and the United States.

In terms of Lithium based battery chemistries, the chemistries of Lithium (Li) Nickel (Ni) Manganese (Mn) Cobalt (Co) Oxide $\left(\mathrm{O}_{2}\right)$ i.e. $\mathrm{LiNiMnCoO}$ and Lithium Cobalt Oxide i.e. $\mathrm{LiCoO}_{2}$ present the highest Energy Density as it is presented in Goonan, 2012, with 100-170 Wh/kg and 100-150 Wh/kg in accordance indicating that apart from Lithium, the expensive Cobalt and Nickel are present for the first battery type and Cobalt for the later battery type.

In terms of recycling, the main motivation in order to be performed, is the expectation of retrieval of the high cost Cobalt and Nickel while secondarily comes the retrieval of Lithium which accounts for $<3 \%$ of the production cost for most of the Li-ion batteries. Due to the high price of Cobalt, Sony, since 1992 has established a collaboration with another entity, in order to retrieve it from Li-ion batteries which have reached their end-of-life (Goonan, 2012). 
Battery recycling data from the United States indicated that the recycling level was proximate to $20 \%$ while up to 2006 Li-ion batteries were not considered to be a hazardous waste. Batteries which have reached their end-of-life in the United States are likely to be still in possession of their owners e.g. at homes, or disposed through the municipality's waste management system e.g. landfills (Goonan, 2012). The expectation for higher recycling level of Li-ion batteries is considerable as it is related to the increase of utilisation of vehicles equipped with batteries as it should follow the effective recycling system applied to lead-acid batteries. If comprehensive recycling of EV batteries takes place, the recovered Lithium could be sufficient for $50 \%$ of the Lithium demand in batteries by the year of 2040 (Goonan, 2012).

The alternative battery type which has been used in vehicles i.e. the NiMH type in the Toyota's hybrid vehicle, the Prius, contains four different rare earth elements which are Lanthanum (La) $60 \%$, Praseodymium (Pr) 20\%, Neodymium (Nd) 10\% and Cerium (Ce) 10\% (Eriksson et al., 2011). Furthermore it also contains $\mathrm{Ni}, \mathrm{Co}, \mathrm{Mn}$ and possibly Aluminium (Al).

So far the discussion focused on batteries, however EVs are also equipped with permanent magnet electric motors. These motors also contain rare earth metals which namely are $\mathrm{Nd}$ in $75 \%, \mathrm{Pr}$ in $25 \%$ as well as Dysprosium (Dy) and Terbium (Tb) in very small quantities. The very small quantities in Dy and Tb are used in order to improve characteristics of the magnet such as temperature stability and coercivity (Eriksson et al., 2011). There can be found two common types of permanent magnets one is with Neodymium, Iron (Fe) and Boron (B) i.e. NdFeB and the other is with Samarium (Sm) and Cobalt i.e. SmCo, however the NdFeB type outperforms the later type in terms of magnetic energy density therefore it is preferable in vehicle applications (Eriksson et al., 2011).

In order to find out about the global reserves and production in rare earths, the unit of Rare Earth Oxide (REO) is utilised which is the total amount of rare earth elements existing in a mineral (Eriksson et al., 2011). According to Figure 7.9, China is the world leader in REO reserves with 55 million metric tons while the second and third places in the world, for individual countries, are occupied by Brazil and the United States with 22 million metric tons and 13 million metric tons in accordance (US Geological Survey, 2014). The size of the reserves as it has been presented for 2013 is determined by two main criteria, the first is related to the production cost and if the process is cost-effective while the other criterion is the extraction/process potentials provided by the today's technology (Eriksson et al., 2011). 


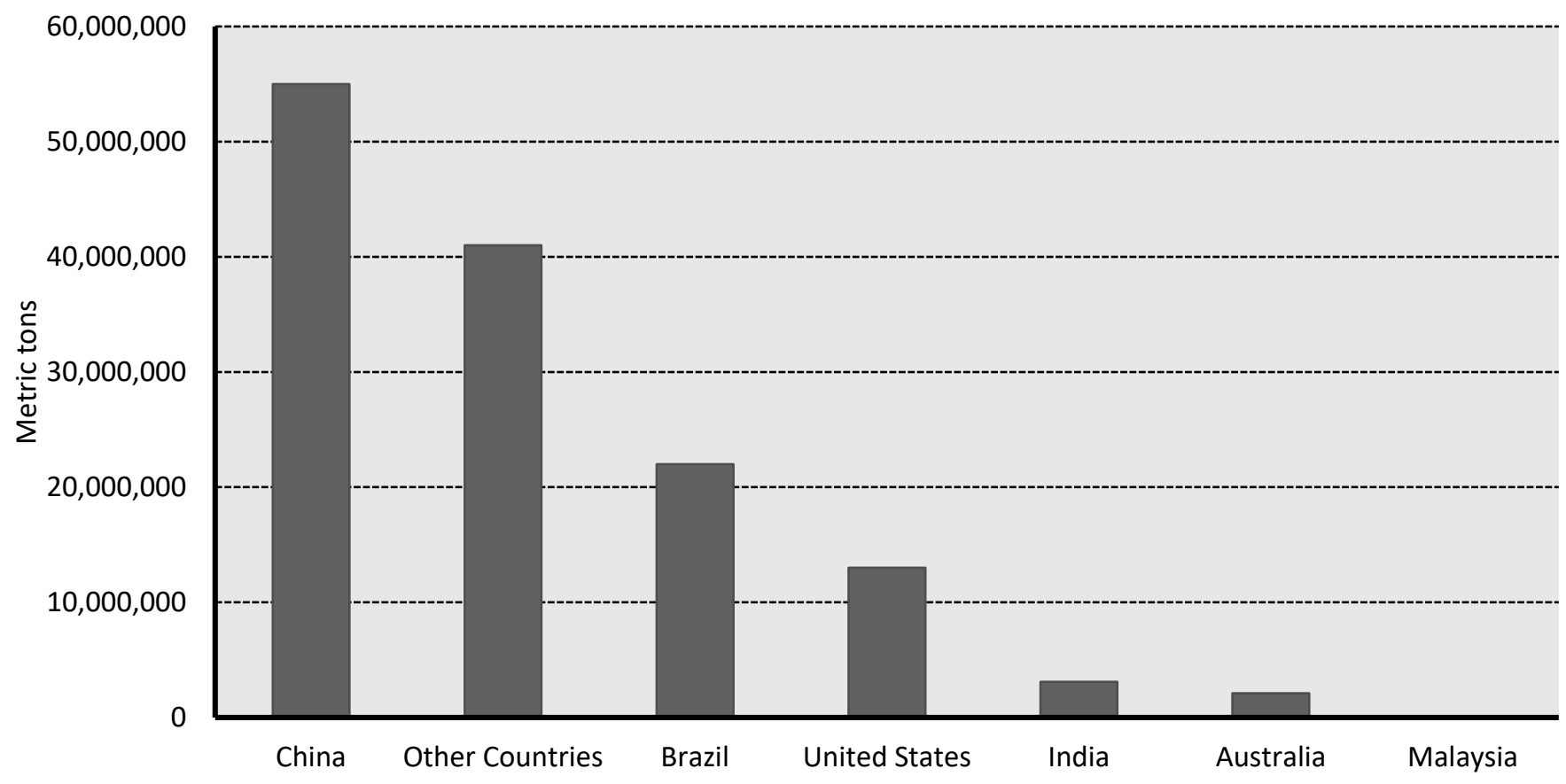

Figure 7.9: REO global reserves in 2013 (US Geological Survey, 2014).

When production is concerned, once again China has dominated over the second country as it can be seen in Figure 7.10 with production to have reached 100,000 metric tons against 4,000 metric tons produced by the United States. In turn the countries India, Russia and Australia can be identified to be in a production range between 2,900 and 2,000 metric tons which is vastly lower than the production leader (US Geological Survey, 2014). Considering the nearly exclusive role of China in the REO production, it is in position to control market prices and to vary its exports by enacting quotas, this gives a strategic advantage to the country which has been used to exercise pressure on Japan when a disagreement between the two countries occurred related to maritime boundaries. This action has concentrated the attention of companies around the globe whose products rely on these supplies (Massari et al., 2013). 


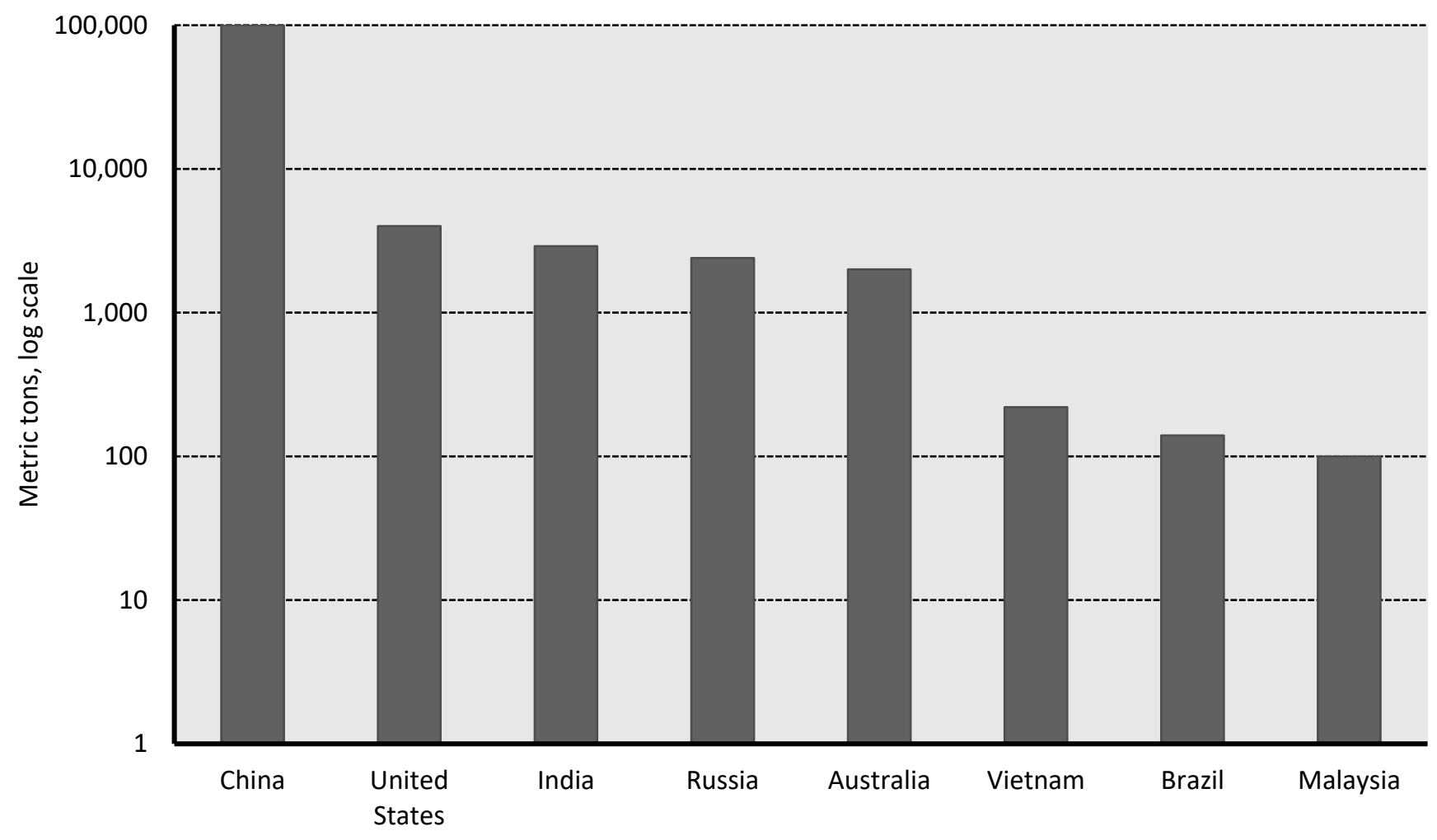

Figure 7.10: REO global production per country in 2013 (US Geological Survey, 2014).

In the context of market control which has been discussed above and towards a market operation with higher degree of independency, several research centres have taken action towards the discovery of artificial substitutes for rare earth elements. In the United States for example, the Department of Energy (DOE) through its funding, it supports the University of Delaware in a joint effort with Hitachi and General Electric (GE), towards the development of strong magnets which will be based on nano-composites instead of rare earths. In Europe, although mineral resources are very low, still it is attempted a reduced dependency on the market by intensely supporting the "urban mining" concept which allows significant amounts of rare earths to be retrieved by performing recycling of hi-tech wastes with the significant advantage that this source of rear earths is already there (Massari et al., 2013).

Regarding the current market prices (December 2014) for the different rare earth metals, which concern this work, are provided in Table 7.2 (Metal-pages, 2014). Furthermore, in the (US DOE report, 2010) and (US DOE report, 2011) are presented two figures with the short-term and medium-term criticality related to the supply risk for each metal. Combining the two sources, the highly priced metals of Table 7.2 can be correlated with the metals subjected to high supply risk. Particularly Tb and Dy which are priced in $825 \$ / \mathrm{kg}$ and $475 \$ / \mathrm{kg}$ in accordance, are also identified to be the metals with the highest supply risk in the (US DOE report, 2010) and (US DOE report, 2011). 


\begin{tabular}{|l|l|}
\hline Metal & Price $\mathbf{( \$ / \mathbf { k g } )}$ \\
\hline Lanthanum (La) & 9.6 \\
\hline Cerium (Ce) & 10 \\
\hline Praseodymium (Pr) & 150 \\
\hline Neodymium (Nd) & 83 \\
\hline Samarium (Sm) & 25 \\
\hline Terbium (Tb) & 825 \\
\hline Dysprosium (Dy) & 475 \\
\hline
\end{tabular}

Table 7.2: Prices for rare earth metals (Metal-pages, 2014).

\section{General method for developing PHEV scheduling systems}

\subsection{Introduction}

This following section outlines a general method for developing scheduling systems for PHEV in the electricity network. The aim of scheduling systems is to coordinate the charging and discharging of PHEV. To minimise the impacts that PHEV have on the electricity network, scheduling systems should aim to promote charging during low load and charge during high load or peak demand periods. In the residential low voltage distribution network low load periods occur late at night, early morning and the middle of the day. Daily peak demand occurs during the early evening. In commercial networks low load occurs during late night and early morning and peak demand occurs during the middle of the day to early afternoon. The load in this circumstance is defined as what the load would be absent the effects that charging and discharging has on the network. For the scheduling systems to operate efficiently a number of subcomponents are required including load forecasting (LF), energy storage availability forecasting (ESA), initial scheduling (IS) and an online control system (OCS). The LF provides information about future load states such that low load and peak demand periods can be identified and quantified. The amount of PHEV connected to the network is up to the discretion of PHEV owner entailing that the precise amount of energy from the PHEV battery banks available for grid support is unknown. Since the actions of people in the aggregate are able to forecast with a reasonable degree of accuracy, the amount of energy storage available may also be able to be forecast. The ESA estimates how much energy storage will be available (number of electric vehicles connected to the electricity network) for supporting the grid. The IS uses the load profile forecasts and the energy storage availability forecasts to create an initial schedule for the day. 
The OCS receives the schedule at the start of the day and throughout the day analyses recent historical load and the activity of PHEV to mitigate scheduling error.

Figure 7.11 displays a general flow chart for forecast based PHEV scheduling systems. For each time interval $(t)$ the scheduling system receives historical load data. Previous PHEV charge and discharge actions are removed from the load data. The load data is then filtered to remove noise from the underlying moving average to prevent scheduling errors. Filtering can be conducted by a variety of techniques such as Kalman flitering, Fourier Transform filtering and seasonal exponential smoothing. If the time interval is the start of the day, the system calls the LF, ESA and IS subcomponents. The forecasted load profiles and the forecasted energy storage availability are passed to IS in order for an initial schedule to be calculated. The calculated schedule is then passed to the OCS that adjusts the schedule in real time throughout the day in response to local conditions to mitigate scheduling error. As an example: if there is less energy storage available than what was initially anticipated, the OCS will reduce the amount of energy discharged into the electricity network. If there is more energy storage available, the OCS may increase the amount of energy discharged into the network. After schedule adjustments have been made, the schedule for the current time interval is dispatched to the PHEV connected to the electricity network.

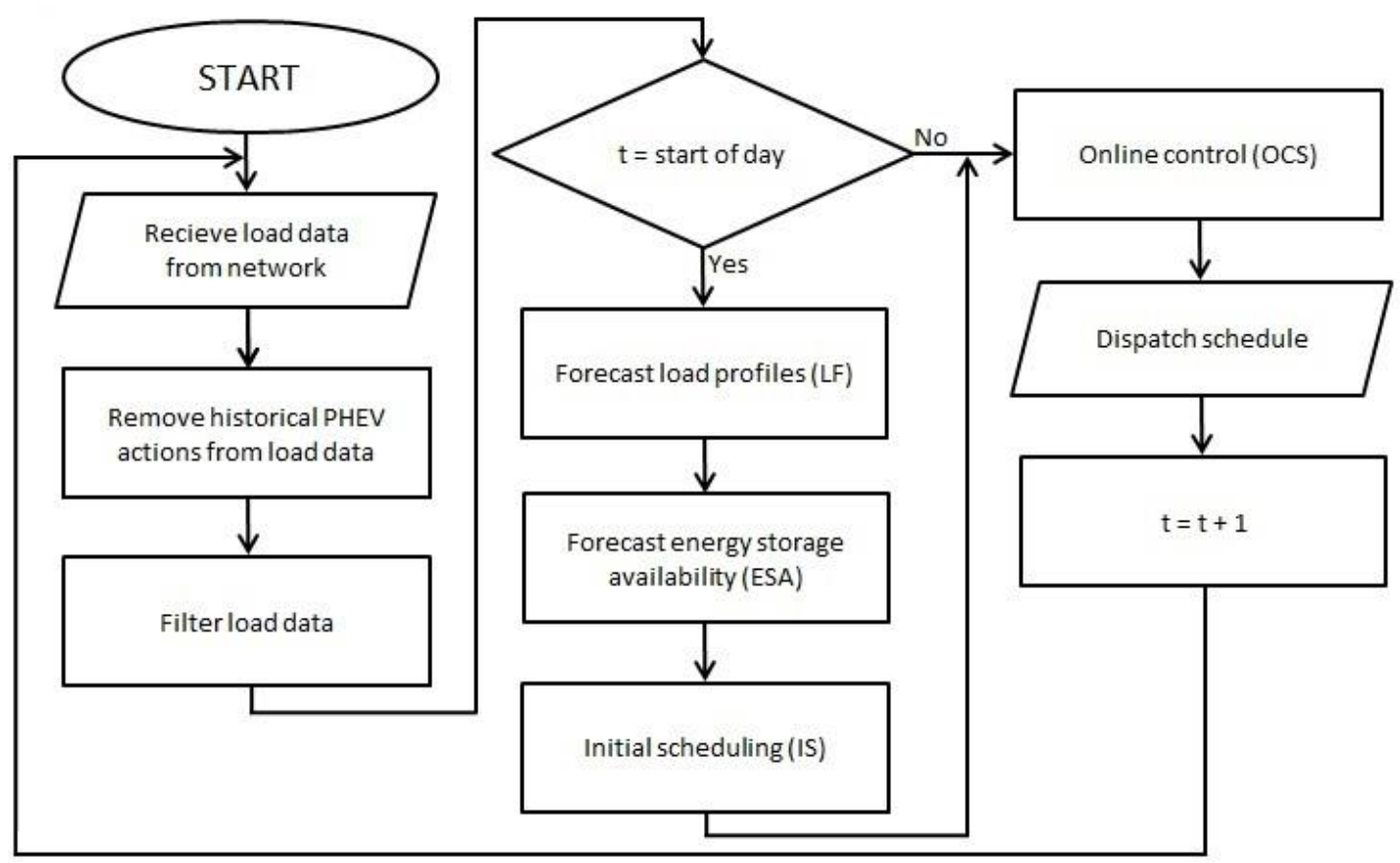

Figure 7.11: General PHEV scheduling system flow chart 


\subsection{Developing load forecast models}

The time series modelling technique is one most common technique used in the electric power industry to forecast load. Time series models can either be univariate or multivariate. The structure of univariate models is such that the variable being forecast is a function of temporal lags of the same variable. Multivariate models are structure such that the dependent variable being forecast is a function of both temporal lags of the same variable and independent variables. In the load forecast space independent variables may include temperature, humidity, day of the week and time of the year (Bennett et al., 2014a; Bennett et al., 2014b). Equation 1 displays a general univariate model and equation 2 displays a general multivariate model.

$$
\begin{aligned}
& y_{t}=\sum_{i=1}^{m} \beta_{i} y_{t-i}+\beta_{0} \\
& y_{t}=\sum_{i=1}^{p} \beta_{i} y_{t-i}+\sum_{j=1}^{q} \alpha_{j} x_{j}+\beta_{0}
\end{aligned}
$$

where $y$ is the variable being forecast, $b$ is a coefficient, $b_{0}$ is a constant, $t$ is the time interval, $i$ is the temporal lag, $m$ is the number of lagged $y$ variables in the function, $x$ represents independent variables, $j$ is the particular independent variable and $q$ is the total number of independent variables.

Univariate time series models fall under the general model called autoregressive integrated moving average $\operatorname{ARIMA}(p, d, q)$. The ' $p$ ' represents the number of discrete differences the time series has undergone. Discrete differencing is engaged in when the presence of a unit root is detected by a unit root test such as the Dicky-Fuller test. The presence of a unit root means that if an exogenous shock occurs its effect permeates through the rest of the time series. The ' $d$ ' is the number of lagged variables are in the model. The ' $q$ ' represents the number of lagged error terms are in the model. Multivariate models fall under the ARIMA with exogenous variable definition (ARIMAX). From the establishment of the definitions, the first stage in the development of a univariate model is to determine the significant periodic patterns in the time series. This can be done using the autocorrelation function, partial autocorrelation function or a Fourier transform. The autocorrelation function is presented in equation 3:

$r_{l}\left(Y_{t}, Y_{t-l}\right)=\frac{1}{m-1} \times \frac{\sum\left(y-u_{t}\right)\left(y_{t-l}-u_{t-l}\right)}{\sigma\left(Y_{t}\right) \sigma\left(Y_{t-l}\right)}, \quad$ for $1 \leq l \leq M$ 
where $r$ is the correlation between time series vectors $Y_{t}$ and $Y_{t-1}, Y_{t}$ is the original time series, $Y_{t-1}$ is the time series with / lags, $u_{t}$ is the mean of $Y_{t}, u_{t-l}$ is the mean of $Y_{t-1}, \sigma\left(Y_{t}\right)$ is the standard deviation of $Y_{t}, \sigma\left(Y_{t-l}\right)$ is the standard deviation of $Y_{t-1}, m$ is the length of $Y_{t}$ and $M$ is the maximum number of lags being investigated. From here a threshold of significance is required to be calculated (equation 4) and lags greater than the threshold are to be included in the model.

$\frac{z_{1-\frac{\alpha}{2}}}{\sqrt{m}}$

where $z$ is a statistic derived from the Student's t-distribution, $\alpha$ is the level of significance and $m$ is the length of $Y_{t}$.

With the significant lags in the time series identified and a function established the coefficients of the model are now required to be calculated. The most common approach is to use least means squared regression as seen in equation 5:

$\hat{\beta}=\left(X^{T} X\right)^{-1} X^{T} Y$

$X=\left[\begin{array}{ccc}x_{1,1} & \cdots & x_{1, p} \\ \vdots & \ddots & \vdots \\ x_{m, 1} & \cdots & x_{m, p}\end{array}\right]$

$Y=\left[\begin{array}{lll}y_{1} & \cdots & y_{m}\end{array}\right]^{T}$

where $\hat{\beta}$ is a column vector of coefficients of length $p, X$ is a matrix of observations where each is row is a new observation and each column pertains to a different variable, $Y$ is a vector of dependent variable observation, $m$ is the number of observation and $p$ is the number of variables in the function. The output of the model is as follows:

$\hat{Y}=X \hat{\beta}+\varepsilon$

$\hat{Y}=\left[\begin{array}{lll}\hat{y}_{1} & \cdots & \hat{y}_{m}\end{array}\right]$ 
where $\hat{Y}$ is the vector of predicted values and $\varepsilon$ is the error term. The calculation of $\hat{Y}$ allows for the determination if there is autocorrelation in the error term (Durbin-Watson test) and the calculation of accuracy statistics. The Durbin-Watson test is calculated using equation 10:

$d=\frac{\sum_{t=1}^{m}\left(e_{t}-e_{t-1}\right)^{2}}{\sum_{t=1}^{m} e_{t}^{2}}$

where $d$ is the Durbin-Watson statistic and $e$ is the error for forecast at time $t$ where the vector of error terms from the model is calculated by $\hat{Y}$ minus $Y . d_{l}$ and $d_{u}$ are critical Durbin-Watson statistics. If $d$ is less than $d_{1}$ then the error is positively autocorrelated and if $(4-d)$ is less than $d_{\text {l }}$ the error is negatively autocorrelated. If $d$ is greater than $d_{l}$ and less than $d_{u}$ there is likely to be no autocorrelation. If autocorrelation is identified the model calculated is required to be altered. Running the autocorrelation function on the error vector will indicate whether there are repeating patterns. If the presence of repeating patterns is identified the model can be adjusted to take the patterns into account.

Once the model has been adjusted to take into account autocorrelation in the error term and nonstationary processes accuracy statistics can be calculated. Common accuracy statistics include the coefficient of determination $\left(R^{2}\right)$, standard deviation of model error or root-mean square error (RMSE), mean absolute error (MAE) and mean absolute percentage error (MAPE). These accuracy statistics are calculated by using the following set of equations:

$R^{2}=1-\frac{\sum_{t=1}^{m}\left(y_{t}-\hat{y}_{t}\right)^{2}}{\sum_{t=1}^{m}(y-u)^{2}}$

where $u$ is the mean of $Y$. The $R^{2}$ statistic ranges from 0 to 1 . A value of 1 entails the model has a perfect fit with the observed time series. Conversely, a value of 0 entails the model does not represent to the observed time series. The closer the value is to 1 the better the fit.

$R M S E=\sqrt{\frac{\sum_{t=1}^{m}\left(y_{t}-\hat{y}_{t}\right)^{2}}{m-p}}$

The RMSE statistic can be used to add a confidence interval to forecasts made using the model. The greater the RMSE the less accurate the model is. The confidence interval can be calculated using equation 13 : 
$C I= \pm z\left(1-\frac{\alpha}{2}, m-2\right) \times R M S E$

where $\mathrm{Cl}$ is the confidence interval. For a forecast $\hat{y}$ and for a level of significance $\alpha$, the forecast is between the upper and lower limits of $\hat{y}-\mathrm{Cl}$ and $\hat{y}+\mathrm{Cl}$.

$M A E=\frac{\sum_{t=1}^{m} a b s\left(y_{t}-\hat{y}_{t}\right)}{m}$

where $M A E$ is the mean absolute error and $a b s()$ is the absolute function. The greater the $M A E$ the less accurate the model is.

$M A P E=\frac{\sum_{t=1}^{m} a b s\left(\left(y_{t}-\hat{y}_{t}\right) / y\right)}{m}$

where MAPE is the mean absolute percentage error. The greater the MAPE the less accurate the model is.

Further testing can be conducted by splitting the time series into a model development set used to estimate the coefficients and a validation set. The validation set is not used in the model development stage. The validation set's input variable data are inputted into the developed models and resulting in a set of forecast for the validation set. The new forecasts can be compared against the validation set's dependent variable observations and accuracy statistics can be calculated. The new accuracy statistics give a better indication of the performance of the model.

To forecast a range of values in the future recursive or rolling forecasting is used. To demonstrate this, a hypothetical model is established in equation 16 :

$\hat{y}_{t}=\beta_{1} y_{t-1}+\beta_{2} y_{t-2}+\beta_{3} y_{t-24}+\beta_{0}$

The model is univariate with three significant lags identified by the autocorrelation function. The autocorrelation function identified a significant period being a 24 hour cycle. In order to forecast the next time interval $t+1$ without knowledge of $y_{t}$ the forecast $\hat{y}_{t}$ is rolled into the model: 
$\hat{y}_{t+1}=\beta_{1} \hat{y}_{t}+\beta_{2} y_{t-1}+\beta_{3} y_{t-23}+\beta_{0}$

The forecast $\hat{y}_{t}$ replaced the observation $y_{t-1}$. To forecast further into the future the pattern of rolling forecasts into the model is repeated. As an example, forecast up to 24 hours ahead using this model, the final forecast in the series is in the form of:

$\hat{y}_{t+23}=\beta_{1} \hat{y}_{t+22}+\beta_{2} \hat{y}_{t+21}+\beta_{3} y_{t-1}+\beta_{0}$

For the purpose of forecasting load profiles and energy storage availability the recursive forecasting method can be used. A drawback of this method is that if significant forecast error is made, the error will permeate throughout the entire forecast period resulting a high likelihood that there will be a significant deviation from the actual load that is to occur in the future. To mitigate this, more forecast can be made throughout the time period allowing for the incorporation of new observations.

\subsection{Initial scheduling}

For a IS to be developed the power electronics that the PHEV scheduling system applies to must be first emulated. Thus models of PHEV battery banks, inverters and the local electricity network are to be included within the IS. The models are not required to be exact replications; they only are required to approximate the system. The models constrain the system such to prevent issues including the exceedance of design ratings and operation of battery banks such that the charge drops below the depth of discharge (DoD) or breaches maximum charge limits (MC). From here, the goals of the scheduling system, and subsequently the IS, govern the rest of the structure surrounding the power electronics components. As an example, a goal may be that the scheduling system only dictates the discharge from battery banks and does not coordinate the charging. PHEV owners may charge their vehicles at will during the day. Using the assumption from the example an algorithm for initial scheduling is provided:

1. The LF and ESA provide load profile forecasts to the IS.

2. Peak demand periods are identified in the load profile forecasts.

3. For the peak for each peak demand period is reduce according to the amount of energy that is available for the specific period. This provides an initial discharge schedule.

4. The initial schedule is dispatched to the OCS. 
Referring to figure 7.5 the area between the peak and the level at which the peak is reduced to is equivalent to the amount of energy storage available constrained by the specifications of the power electronics of the system.

\subsection{Online control system}

The goal of the OCS is to mitigate scheduling error that may occur due to forecast inaccuracy. There are two main types of scheduling error. The first is a mismatch between the actual peak load and the observed peak load. This would lead to an inefficient discharge schedule that may not sufficiently reduce peaks. The second is an occurrence of insufficient energy to discharge into the electricity network across the peak demand period. A method of mitigating scheduling error is:

1. For each time interval the previous time interval's load and available energy storage data is collected and used to update load and energy storage availability forecasts.

2. A simulation is run with the new data to determine if the initial schedule is not sufficient.

3. If the schedule is not sufficient the amount of energy being discharge into the network is either increased or decreased.

\section{Conclusion}

The chapter provides a summary of the barriers and opportunities of widespread PHEV. Specifically, it examined the economic, social and environmental dimensions of PHEV. The economic dimension discussed how PHEV could have a potential negative impact on the electricity network if there was unregulated battery charging and discharge. The major problem being the requirement for additional distribution infrastructure to cope with the increased demand for energy created through PHEV operation as well as the associated power quality issues. Social issues could arise if it was perceived that PHEV owners were being subsidised by electricity consumers. One solution recommended herein was to restrict PHEV charging by technical or regulatory means. A second type of solution was proposed through the use of price incentives which would allow owners to use their PHEV at will but also pay according to their use. The social dimension covered individuals' likely take-up of PHEV according to their attitudes and beliefs. For the rollout of PHEV to be successful, car designers through to city planners need to make PHEV and the necessary infrastructure to support it as equally convenient to current transport options. Some strategies to achieve this include making PHEV servicing and maintenance convenient, providing infrastructure for PHEV owners (i.e. charging or battery swap stations), addressing safety concerns and providing the right 
information to society to change perceptions. The environmental dimension alluded that PHEV have the potential to yield environmental gains over conventional vehicles. PHEV tend to perform better in terms of reducing local air pollution. PHEV proliferation means that there will be substantial battery waste issues over time, which mandates the proper reuse and recycling of batteries and the invention of more advanced battery technology that will minimise environmental impact. PHEV charging from the electricity network means that there is still a reliance on fossil fuels in most cities; hence, there are minimal effects on reducing or abating greenhouse gas emissions unless city electricity generation has a reasonable proportion of renewables. Addressing the complete spectrum of economic, social and environmental dimensions of PHEV is paramount before this technology will push aside the age of the internal combustion engine.

\section{References}

Andersson, S. L., Elofsson, A. K., Galus, M. D., Göransson, L., Karlsson, S., Johnsson, F., \& Andersson, G. (2010). Plug-in hybrid electric vehicles as regulating power providers: Case studies of Sweden and Germany. Energy policy, 38(6), 2751-2762.

Bennett, C. J., Stewart, R. A., \& Lu, J. W. (2014a). Forecasting low voltage distribution network demand profiles using a pattern recognition based expert system. Energy, 67, 200-212.

Bennett, C., Stewart, R. A., \& Lu, J. (2014b). Autoregressive with Exogenous Variables and Neural Network Short-Term Load Forecast Models for Residential Low Voltage Distribution Networks. Energies, 7(5), 29382960.

Brooks, A. N. (2002). Vehicle-to-grid demonstration project: Grid regulation ancillary service with a battery electric vehicle. California Environmental Protection Agency, Air Resources Board, Research Division.

Chatzivasileiadi, A., Ampatzi, E., \& Knight, I. (2013). Characteristics of electrical energy storage technologies and their applications in buildings. Renewable and Sustainable Energy Reviews, 25, 814-830.

Cocron, P. and Krems, J.F. (2013) Driver perceptions of the safety implications of quiet electric vehicles. Accident Analysis \& Prevention, 58, 122-131. 
Deilami, S., Masoum, A. S., Moses, P. S., \& Masoum, M. A. (2011). Real-time coordination of plug-in electric vehicle charging in smart grids to minimize power losses and improve voltage profile. Smart Grid, IEEE Transactions on, 2(3), 456-467.

Eriksson, T., \& Olsson, D. (2011). The Product Chains of Rare Earth Elements Used in Permanent Magnets and NiMH Batteries for Electric Vehicles.

Fluhr, J., Ahlert, K. H., \& Weinhardt, C. (2010). A stochastic model for simulating the availability of electric vehicles for services to the power grid. In System Sciences (HICSS), 2010 43rd Hawaii International Conference on (pp. 1-10). IEEE.

Goonan, T.G., (2012). Lithium use in batteries: US Geological Survey Circular 1371, 14 p., available at http://pubs.usgs.gov/circ/1371/.

Heymans, C. Walker, S.B. Young, S.B. and Fowler, M. (2014) Economic analysis of second use electric vehicle batteries for residential energy storage and load-levelling. Energy Policy, 71, 22-30.

Humpreys, K.K. Placet, M., Singh, M. Life-cycle assessment of electric vehicles in the United States. In 31st Intersociety Energy Conversion Engineering Conference (IECEC).IEEE 11-16 Aug 1996. pp. 2124 - 2127.

Kesler, S.E., Gruber, P.W., Medina, P. A., Keoleian, G. A., Everson, M.P., Wallington, T. J. (2012). Global lithium resources: Relative importance of pegmatite, brine and other deposits. Ore Geology Reviews, 48, 55-69.

Khan, R.H. and Khan, J.Y. (2013) A comprehensive review of the application characteristics and traffic requirements of a smart grid communications network. Computer Networks, 57(3), 825-845.

Lemoine, D. M., Kammen, D. M., \& Farrell, A. E. (2008). An innovation and policy agenda for commercially competitive plug-in hybrid electric vehicles. Environmental Research Letters, 3(1), 014003.

Lopes, J. A. P., Soares, F. J., \& Almeida, P. M. R. (2011). Integration of electric vehicles in the electric power system. Proceedings of the IEEE, 99(1), 168-183. 
Lu, L. Han, X. Li, J. Hua, J. and Ouyang, M. (2013) A review on the key issues for lithium-ion battery management in electric vehicles. Journal of Power Sources, 226, 272-288.

Mak, H-Y. Rong, Y. and Shen Z-J. M. (2013) Infrastructure planning for electric vehicles with battery swapping. Management Science, 59(7), 1557-1575.

Massari, S., \& Ruberti, M. (2013). Rare earth elements as critical raw materials: Focus on international markets and future strategies. Resources Policy, 38(1), 36-43.

Messagie, M., Boureima, F., Matheys, J., Sergeant, N., Turcksin, L., Macharis, C., Van Mierlo, J. Life Cycle Assessment of conventional and alternative small passenger vehicles in Belgium. In Vehicle Power and Propulsion Conference (VPPC).IEEE 1-3 Sept. 2010. pp. 1 - 5.

Metal-pages, (2014). Available at: http://www.metal-pages.com/metalprices/rareearths/ [Accessed 5 December 2014].

Mohd, A., Ortjohann, E., Schmelter, A., Hamsic, N., \& Morton, D. (2008, June). Challenges in integrating distributed energy storage systems into future smart grid. In Industrial Electronics, 2008. ISIE 2008. IEEE International Symposium on (pp. 1627-1632). IEEE.

Nelson, T., Simshauser, P., \& Kelley, S. (2011). Australian residential solar feed-in tariffs: Industry stimulus or regressive form of taxation?. Economic Analysis and Policy, 41(2), 113.

Peterson, S. B., Whitacre, J. F., \& Apt, J. (2010). The economics of using plug-in hybrid electric vehicle battery packs for grid storage. Journal of Power Sources, 195(8), 2377-2384.

Putrus, G. A., Suwanapingkarl, P., Johnston, D., Bentley, E. C., \& Narayana, M. (2009, September). Impact of electric vehicles on power distribution networks. In Vehicle Power and Propulsion Conference, 2009. VPPC'09. IEEE (pp. 827-831). IEEE.

Qian, K., Zhou, C., Allan, M., \& Yuan, Y. (2011). Modeling of load demand due to EV battery charging in distribution systems. Power Systems, IEEE Transactions on, 26(2), 802-810. 
Renaldi, Yuanditra, W., Raharno, S., Martawirya, Y.Y. Environmental consideration in materials selection for electric vehicles. In Joint International Conference on Rural Information \& Communication Technology and Electric-Vehicle Technology (rICT \& ICeV-T). IEEE 26-28 Nov. 2013. pp. 1 - 4.

Simshauser, P., Nelson, T., \& Doan, T. (2011). The boomerang paradox, part II: policy prescriptions for reducing fuel poverty in Australia. The Electricity Journal, 24(2), 63-75.

Steinhilber, S. Wells, P. Thankappan, S. (2013) Socio-technical inertia: Understanding the barriers to electric vehicles. Energy Policy, 60, 531-539.

Strbac, G. (2008). Demand side management: Benefits and challenges. Energy policy, 36(12), 4419-4426.

US DOE report, (2011). U.S. Department of Energy: Critical Materials Strategy.

US DOE report, (2010). U.S. Department of Energy: Critical Materials Strategy.

US Geological Survey, (2014). Annual publications: Mineral Commodity Summaries: Rare Earths: 2014. [online] Available at: http://minerals.usgs.gov/minerals/pubs/commodity/rare_earths/ [Accessed 4 December 2014].

Ziefle, M. Beul-Leusmann, S. Kasugai, K. Schwalm, M. (2014) Design, user experience, and usability. User experience design for everyday life applications and services. Lecture notes in computer science, 8519, 628-639. 